\title{
Clinical and genetic analyses and treatment outcomes of patients with lateralized overgrowth
}

\author{
Yoon-Myung Kim \\ University of Ulsan \\ Yena Lee \\ Asan Medical Center \\ Yunha Choi \\ Asan Medical Center \\ In-Hee Choi \\ University of Ulsan \\ Sun Hee Heo \\ Asan Medical Center \\ Jung Min Choi \\ Asan Medical Center \\ Hyo-Sang Do \\ Asan Medical Center \\ Ja-Hyun Jang \\ Samsung Medical Center \\ Mi-Sun Yum \\ University of Ulsan \\ Han-Wook Yoo \\ University of Ulsan \\ Beom Hee Lee ( $\sim$ bhlee@amc.seoul.kr) \\ University of Ulsan
}

\section{Research Article}

Keywords: PIK3CA-related segmental overgrowth syndrome, Lateralized overgrowth, Alpelisib, Targeted exome sequencing

Posted Date: June 21st, 2022

DOI: https://doi.org/10.21203/rs.3.rs-717104/v2

License: @ (i) This work is licensed under a Creative Commons Attribution 4.0 International License. Read Full License 


\begin{abstract}
Background: The genetic features and treatment strategies of lateralized overgrowth have been elusive. We performed this study to analyze the genetic characteristics and treatment results of propranolol- or alpelisib-treated patients with lateralized overgrowth.
\end{abstract}

Methods: Fifteen patients with lateralized overgrowth were involved. Clinical characteristics and whole-body magnetic resonance imaging (WB-MRI) findings were evaluated. Targeted exome sequencing with a gene panel of affected tissue and peripheral white blood cells was performed. Propranolol was administered and treatment results were evaluated. The PIK3CA inhibitor alpelisib was prescribed via a managed access program.

Results: The identified mutations were PIK3CA $(\mathrm{n}=7), \operatorname{KRAS}(\mathrm{n}=2), \operatorname{PTEN}(\mathrm{n}=1), \operatorname{MAP} 2 K 3(\mathrm{n}=1)$, GNAQ $(\mathrm{n}=1), \operatorname{TBC} 1 D 4(\mathrm{n}=1)$, and TEK $(\mathrm{n}=1)$. Propranolol was prescribed in 12 patients, and 7 experienced mild improvement of symptoms. Alpelisib was prescribed in two patients with a PIK3CA mutation, and the reduction of proliferated masses after 1 year of treatment was proved by WB-MRI .

Conclusions: Targeted exome sequencing identified various genetic features of lateralized overgrowth. Propranolol could be applied as an adjuvant therapy for reducing vascular symptoms, but a PIK3CA inhibitor would be the primary therapeutic strategy for PIK3CA-related overgrowth syndrome.

\title{
Introduction
}

Overgrowth syndrome (OS) refers to a group of disorders with abnormal, excessive tissue proliferation, which can be classified as general or segmental, including the Beckwith-Wiedemann syndrome, Sotos syndrome, Proteus syndrome, and phosphoinositide-3-kinase, catalytic, alpha polypeptide (PIK3CA) -related OS (PROS) ${ }^{1,2}$. These disorders are often accompanied by symptoms of lateralized overgrowth caused by somatic mosaicism ${ }^{2}$.

The PI3K/Protein Kinase B (AKT)/mechanistic target of rapamycin (mTOR) signaling pathway has major roles in cell growth, proliferation, and differentiation

3. The Ras family of small GTPase proteins (RAS)/mitogen-activated protein kinases (MAPK) pathway also interacts with the PI3K/AKT/mTOR pathway, and phosphatase and tensin homolog (PTEN) and tuberous sclerosis complex (TSC) 1 and 2 are the negative regulators ${ }^{3}$.

PIK3CA mutations account for Klippel-Trenaunay syndrome (KTS), Megalencephaly-Capillary Malformation syndrome (M-CM), congenital lipomatous lateralized overgrowth of the trunk, lymphatic, capillary, venous, and combined-type vascular malformations, epidermal nevi, skeletal, and spinal anomalies (CLOVES) syndrome ${ }^{3}$. Additional OSs such as Proteus syndrome is related to the activation of the PI3K-AKT-mTOR pathway. Most cases of BeckwithWiedemann syndrome and some cases of isolated lateralized overgrowth are caused by methylation defects on the region of chromosome $11 \mathrm{p} 15^{2}$.

There is an ongoing effort to treat OS using inhibitors of PI3K, AKT, or mTOR ${ }^{3}$, but no therapeutic inhibitor has been approved to date. Recently, a PIK3CA inhibitor named alpelisib (PIQRAY, Novartis Pharmaceuticals Corporation) was proposed to show efficacy in patients with PROS/CLOVES; this drug is now under investigation in clinical trials ${ }^{4,5}$.

Propranolol, a beta-blocker, has been widely used for the treatment of hemangiomas, and several previous studies have suggested that propranolol might negatively regulate the AKT/mTOR pathway ${ }^{6-8}$. Indeed, propranolol has shown partial efficacy in the regression of vascular masses in patients with KTS 9,10 .

In the present study, the genetic analysis, including PIK3CA and its related pathways, of patients with lateralized overgrowth were explored. In addition, we report the efficacy and safety of long-term propranolol treatment in segmental OS and of alpelisib in cases with somatic PIK3CA mutation.

\section{Materials And Methods}

\section{Subjects and evaluation of clinical characteristics}

This study was a single-center, open-label, non-randomized, observational study performed at the Asan Medical Center, Seoul, Korea, from February 2014 to May 2020. The study was approved by the Institutional Review Board of Asan Medical Center (no. 2020 - 1628). Written informed consent was obtained from all participants and all methods were performed in accordance with the relevant guidelines and regulations. Fifteen patients with clinical features of lateralized overgrowth were enrolled. The affected areas were evaluated by physical examination and whole-body magnetic resonance imaging (WB-MRI). Evidence of cutaneous capillary malformation, such as port-wine stain, telangiectasia and angiokeratoma, varicosities and hypertrophy of soft tissue, was analyzed. Medical photographs were taken yearly.

\section{Genetic analysis}

Genetic analysis was performed using a customized gene panel. Exome sequencing was performed using genomic DNA extracted from the affected tissue and peripheral blood leukocytes. The affected tissue was obtained by skin biopsy from the regions with hypertrophy or cutaneous capillary malformation. Exomes were captured using a Celemics Custom Panel (Celemics Inc., Seoul, Korea), which enriches a 372,068 bp region spanning 143 genes related to cell signaling pathways (Additional File 1: Table S1). Sequencing was performed on the NextSeq platform (Illumina Inc., San Diego, CA, US). The mean depth of coverage was 878 reads per base with a $30 X$ coverage of $99.3 \%$ for the affected tissue-extracted DNA sequencing. The mean depth of coverage was 346 reads per base with a $30 \mathrm{X}$ coverage of $99.0 \%$ for the blood-extracted DNA sequencing. Sequence reads were aligned to the reference genome, hg 19 , using Burrows-Wheeler Aligner (version 0.7.12, MEM algorithm) ${ }^{11}$. Duplicate reads were removed using Picard tools version 1.96. The Genome Analysis Toolkit (GATK version 3.7) was used for local realignment and base quality recalibration. Variant calling was performed using GATK MuTect2 and HaplotypeCaller ${ }^{12}$ for tissue and blood, respectively. Common variants with minor allele frequency $\geq 1 \%$ were filtered out using public databases such as the Genome Aggregation Database, Exome Variant Server, and 1000 Genomes Browser. Population-specific common variants were further filtered out using the Korean

Page $2 / 11$ 
Reference Genome Database. Variants were annotated using Variant Effect Predictor 88 and Oncotator (version 1.9.2). Candidate variants were manually curated using Integrated Genome Viewer.

\section{Treatment strategies}

Treatment with propranolol was initiated at a dose of $0.5 \mathrm{mg} / \mathrm{kg} / \mathrm{day}$, which was subsequently increased to a maximum dose of $4 \mathrm{mg} / \mathrm{kg} / \mathrm{day}$. WB-MRI findings, erythrocyte sedimentation rate (ESR), and vascular endothelial growth factor levels, as well as other representative cytokine levels, were evaluated before and after the propranolol treatment. Cytokine evaluation was performed using the Millipore Human Cytokine/Chemokine Magnetic Bead Panel (Merck KGaA Inc., Darmstadt, Germany) at an interval of 6 months. Responses to the SF-36 version 2 short-form health survey questionnaire ${ }^{13}$ were acquired every 6 months to evaluate changes in quality of life. SF-36 questions yield eight subscales and two summaries of physical and mental component scores.

Alpelisib, an alpha-specific PI3K inhibitor approved in the United States for medical use in advanced or metastatic breast cancer with PIK3CA mutation since May 2019, was administrated in two patients for clinical trial via a managed access program (MAP) approved by Novartis Pharmaceuticals Corporation (Novartis/CBYL719X2001I MAP ID 17746/17751). The application of alpelisib was available only for two volunteers. Alpelisib was provided as a 50 mg or $200 \mathrm{mg}$ coated tablet and administered orally once daily. A fixed dose of $250 \mathrm{mg}$ was administrated to an adult patient and $50 \mathrm{mg}$ to a pediatric patient as previously described ${ }^{4}$ and according to the manufacturer's instruction. The volume change in the extremities was measured and compared using WB-MRI.

\section{Results}

\section{Clinical presentation and diagnosis}

Fifteen patients ( 11 males and 4 females) with a mean age of $14.8 \pm 19.5$ years (range, $0.25-53$ years) were enrolled. None of the patients had a positive family history. Ten patients $(9 / 15,60 \%)$ showed overgrowth of the lower extremities-five in the right, two in the left, and two in both. Six patients $(6 / 15,40 \%)$ showed overgrowth of both the lower and upper extremities-four in the left and one in the right (Additional File 1: Fig. S1). Eight patients showed limb length discrepancy. Cutaneous capillary malformation presented as port-wine stain in 11 patients (11/15, 73.3\%). Patient 10 had a pigmentary skin macules presenting as epidermal nevi on the left trunk and extremities (Fig. 1). Venous engorgement of extremities was identified in six patients (6/15, 40\%) using WBMRI. Other clinical features included splenomegaly with lymphatic malformation, leg or spinal arteriovenous malformation ( $n=2,13.3 \%$ ), facial asymmetry with hemifacial bone prominence $(n=1,6.7 \%)$, hemimegalencephaly $(n=1,6.7 \%)$, seizure $(n=1,6.7 \%)$, and one-sided blindness $(n=1,6.7 \%)($ Table 1$)$. 
Table 1

Clinical characteristics of patients with lateralized overgrowth syndrome in the present study.

\begin{tabular}{|c|c|c|c|c|c|}
\hline \multirow{2}{*}{$\begin{array}{l}\text { Patient } \\
\text { (Sex/age) }\end{array}$} & \multicolumn{4}{|c|}{ Clinical features } & \multirow[t]{2}{*}{ Genetic diagnosis (mutated gene) } \\
\hline & $\begin{array}{l}\text { Lateralized } \\
\text { overgrowth }\end{array}$ & $\begin{array}{l}\text { Cutaneous capillary } \\
\text { malformation }\end{array}$ & Varicosities & Others & \\
\hline $1(M / 7 y)$ & Right leg & Right leg & + & - & PROS (PIK3CA) \\
\hline $2(M / 8 y)$ & Left arm leg & Trunk, both arms, left leg & - & Seizure, ipsilateral long 2nd toe & PROS (PIK3CA) \\
\hline 3 (F/39y) & $\begin{array}{l}\text { Left arm } \\
\text { and leg }\end{array}$ & Face, trunk, Left arm & + & - & PROS (PIK3CA) \\
\hline$\stackrel{4}{(\mathrm{M} / 10 \mathrm{~m})}$ & Both legs & Left neck and shoulder & - & Hemimegalencephaly & PROS (PIK3CA) \\
\hline 5 (F/53y) & Both legs & Both legs & + & Pulmonary thromboembolism & PROS (PIK3CA) \\
\hline $6(\mathrm{~F} / 4 \mathrm{~m})$ & $\begin{array}{l}\text { Left arm } \\
\text { and leg }\end{array}$ & Trunk, left face, neck & - & - & PROS (PIK3CA) \\
\hline $7(\mathrm{M} / 4 \mathrm{~m})$ & $\begin{array}{l}\text { Right arm } \\
\text { and leg }\end{array}$ & Trunk, both arms and legs & + & - & PROS (PIK3CA) \\
\hline $8(M / 7 y)$ & Right legs & None & - & - & RAS/MAPK-related OS (KRAS) \\
\hline $9(M / 2 y)$ & Right legs & None & - & $\begin{array}{l}\text { Lumbosacral AVM, Lymphatic } \\
\text { malformation }\end{array}$ & $\begin{array}{l}\text { RAS/MAPK-related OS } \\
(K R A S)\end{array}$ \\
\hline $10(F / 2 y)$ & $\begin{array}{l}\text { Left arm } \\
\text { and both } \\
\text { legs }\end{array}$ & None & + & $\begin{array}{l}\text { Epidermal nevi, Chest wall } \\
\text { AVM, Lymphatic malformation }\end{array}$ & $\begin{array}{l}\text { PTEN hamartoma tumor syndrome; PTEN } \\
\text { related Proteus syndrome (PTEN) }\end{array}$ \\
\hline $\begin{array}{l}11 \\
(\mathrm{M} / 3 \mathrm{y})\end{array}$ & Left leg & None & - & Left tibial hypertrophy & RAS/MAPK-related OS (MAP2K3) \\
\hline $\begin{array}{l}12 \\
(M / 6 y)\end{array}$ & $\begin{array}{l}\text { Right arm } \\
\text { and leg }\end{array}$ & $\begin{array}{l}\text { Face, neck, right side of } \\
\text { trunk, right arm, both legs }\end{array}$ & + & $\begin{array}{l}\text { Ipsilateral eye blindness, } \\
\text { mental retardation }\end{array}$ & Sturge-Weber syndrome (GNAQ) \\
\hline $\begin{array}{l}13 \\
(\mathrm{M} / 47 \mathrm{y})\end{array}$ & Right leg & Right leg & - & - & $(T B C 1 D 4)$ \\
\hline $\begin{array}{l}14 \\
(\mathrm{M} / 5 \mathrm{y})\end{array}$ & Left leg & Left leg & - & - & TEK-related vascular malformation (TEK) \\
\hline $\begin{array}{l}15 \\
(M / 43 y)\end{array}$ & Right leg & $\begin{array}{l}\text { Face, neck, trunk, left arm, } \\
\text { both legs }\end{array}$ & - & - & Not determined \\
\hline
\end{tabular}

\section{Genetic diagnosis}

The somatic variant was considered significant if the variant was not observed in a public genome database, was predicted to alter protein function significantly according to multiple in silico analyses and the American College of Medical Genetics (ACMG) guidelines ${ }^{14}$, and was then observed in the affected tissue with a variant allele frequency (VAF) $>0.01$ (Tables 2 and 3 ). The VAF in the affected tissue was also compared to that in non-affected tissue (blood leukocytes) of each patient. Significant mutations were observed in the affected tissue of 14 patients (93.3\%) with the exception for patient 15. The identical mutations were also identified in the blood of three patients. Seven patients (46.7\%) carried a PIK3CA mutation; two patients (13.3\%) had a KRAS mutation. Other identified mutations included PTEN $(\mathrm{n}=1,6.7 \%), \operatorname{MAP} 2 K 3(\mathrm{n}=1,6.7 \%)$, GNAQ $(\mathrm{n}=1,6.7 \%)$, TBC1D4 $(\mathrm{n}=1,6.7 \%)$, and TEK $(\mathrm{n}=1,6.7 \%)$ (Table 2). According to the ACMG guidelines, seven variants were predicted as pathogenic, five variants as likely pathogenic, and two variants as "variant of unknown significance" (VUS). All of the identified mutations, except for TEK, can be found in the Catalogue of Somatic Mutations in Cancer (COSMIC) database ${ }^{15}$. The identified PIK3CA mutations have been previously reported in other patients with PROS ${ }^{16,17}$, and the KRAS and TEK mutations in patients with vascular malformation ${ }^{18,19}$, but the MAP2K3 and TBC1D4 mutations have not been previously reported. 
Table 2

Genetic characteristics of identified mutations in patients.

\begin{tabular}{|c|c|c|c|c|c|c|c|c|c|}
\hline Patient & $\begin{array}{l}\text { Mutated } \\
\text { gene }\end{array}$ & DNA sequence & $\begin{array}{l}\text { Amino acid } \\
\text { change }\end{array}$ & $\begin{array}{l}\text { VAF } \\
\text { (tissue) }\end{array}$ & $\begin{array}{l}\text { VAF } \\
\text { (blood) }\end{array}$ & $\begin{array}{l}\text { Depth } \\
(X) \\
\text { (tissue) }\end{array}$ & $\begin{array}{l}\text { Depth } \\
(X) \\
\text { (blood) }\end{array}$ & COSMIC ID & Biopsy site and lesion \\
\hline 1 & PIK3CA & c. $1636 \mathrm{C}>\mathrm{A}$ & p.GIn546Lys & 0.048 & 0 & 513 & 594 & CosM766 & $\begin{array}{l}\text { Right thigh, cutaneous } \\
\text { capillary malformation }\end{array}$ \\
\hline 2 & PIK3CA & c. $2740 \mathrm{G}>\mathrm{A}$ & p.Gly914Arg & 0.182 & 0 & 765 & 326 & CosM3205660 & $\begin{array}{l}\text { Left arm, cutaneous } \\
\text { capillary malformation }\end{array}$ \\
\hline 3 & PIK3CA & c. $1345 \mathrm{C}>\mathrm{A}$ & p.Pro449Thr & 0.131 & 0 & 721 & 323 & CosM18601 & $\begin{array}{l}\text { Left arm, cutaneous } \\
\text { capillary malformation }\end{array}$ \\
\hline 4 & PIK3CA & c. $1633 \mathrm{G}>\mathrm{A}$ & p.Glu545Lys & 0.023 & 0 & 633 & 352 & CosM763 & $\begin{array}{l}\text { Left leg, cutaneous capillary } \\
\text { malformation }\end{array}$ \\
\hline 5 & PIK3CA & c. $1357 \mathrm{G}>\mathrm{A}$ & p.Glu453Lys & 0.127 & 0 & 1554 & 398 & CosM12584 & $\begin{array}{l}\text { Left leg, cutaneous capillary } \\
\text { malformation }\end{array}$ \\
\hline 6 & PIKЗCA & c. $3073 \mathrm{~A}>\mathrm{G}$ & p.Thr1025Ala & 0.081 & 0 & 1149 & 314 & CosM771 & Neck, hemangioma \\
\hline 7 & PIK3CA & c. $2908 \mathrm{G}>\mathrm{A}$ & p.Glu970Lys & 0.023 & 0.036 & 890 & 239 & COSM94980 & $\begin{array}{l}\text { Lower leg, cutaneous } \\
\text { capillary malformation }\end{array}$ \\
\hline 8 & KRAS & c. $35 \mathrm{G}>\mathrm{A}$ & p.Gly12Asp & 0.041 & 0 & 1080 & 212 & cosm521 & $\begin{array}{l}\text { Right lower leg, skin of } \\
\text { overgrowth lesion }\end{array}$ \\
\hline 9 & $K R A S$ & c. $35 \mathrm{G}>\mathrm{A}$ & p.Gly12Asp & 0.058 & 0 & 571 & 391 & CosM521 & $\begin{array}{l}\text { Right lower leg, skin of } \\
\text { overgrowth lesion }\end{array}$ \\
\hline 10 & PTEN & c. $755 \mathrm{~A}>\mathrm{T}$ & p.Asp252Val & 0.712 & 0.481 & 880 & 281 & CosM3368151 & $\begin{array}{l}\text { Abdomen skin, epidermal } \\
\text { nevus }\end{array}$ \\
\hline 11 & MAP2K3 & c. $696+1 G>A$ & p.(?) & 0.042 & 0.088 & 796 & 341 & CosM560209 & $\begin{array}{l}\text { Left inguinal area, skin of } \\
\text { overgrowth lesion }\end{array}$ \\
\hline 12 & $G N A Q$ & c. $548 \mathrm{G}>\mathrm{A}$ & p.Arg183GIn & 0.039 & 0 & 1038 & 248 & CosM52975 & $\begin{array}{l}\text { Right flank area, nevus } \\
\text { flammeus }\end{array}$ \\
\hline 13 & TBC1D4 & c. $667 \mathrm{G}>\mathrm{A}$ & p.Asp223Asn & 0.026 & 0 & 952 & 273 & CoSM6797461 & $\begin{array}{l}\text { Right lower leg, skin of } \\
\text { overgrowth lesion }\end{array}$ \\
\hline 14 & TEK & c.3324_3334del & $\begin{array}{l}\text { p.Glu1109Leufs } \\
\text { Ter5 }\end{array}$ & 0.046 & 0 & 544 & 567 & - & $\begin{array}{l}\text { Left buttock, skin of } \\
\text { overgrowth lesion }\end{array}$ \\
\hline 15 & Not found & & - & - & - & 1074 & 322 & - & $\begin{array}{l}\text { Abdomen, cutaneous } \\
\text { capillary malformation }\end{array}$ \\
\hline
\end{tabular}


Table 3

In silico identification of mutations in patients.

\begin{tabular}{|c|c|c|c|c|c|c|c|c|}
\hline Patient & $\begin{array}{l}\text { Mutated } \\
\text { gene }\end{array}$ & $\begin{array}{l}\text { DNA sequence } \\
\text { change }\end{array}$ & SIFT & Mutation taster & LRT & PROVEAN & $\begin{array}{l}\text { CADD phred } \\
\text { score }\end{array}$ & $\begin{array}{l}\text { Predicted } \\
\text { pathogenicity* }\end{array}$ \\
\hline 1 & PIK3CA & c. $1636 \mathrm{C}>\mathrm{A}$ & Tolerated & $\begin{array}{l}\text { Disease } \\
\text { causing }\end{array}$ & Deleterious & Neutral & 25.2 & Pathogenic \\
\hline 2 & PIK $3 C A$ & c. $2740 \mathrm{G}>\mathrm{A}$ & Deleterious & $\begin{array}{l}\text { Disease } \\
\text { causing }\end{array}$ & Deleterious & Deleterious & 31 & Pathogenic \\
\hline 3 & PIKЗCA & c. $1345 \mathrm{C}>\mathrm{A}$ & Deleterious & $\begin{array}{l}\text { Disease } \\
\text { causing }\end{array}$ & Deleterious & Deleterious & 28.4 & Likely pathogenic \\
\hline 4 & PIK3CA & c. $1633 \mathrm{G}>\mathrm{A}$ & Deleterious & $\begin{array}{l}\text { Disease } \\
\text { causing }\end{array}$ & Deleterious & Deleterious & 33 & Pathogenic \\
\hline 5 & PIK3CA & c. $1357 \mathrm{G}>\mathrm{A}$ & Tolerated & $\begin{array}{l}\text { Disease } \\
\text { causing }\end{array}$ & Deleterious & Neutral & 32 & Likely pathogenic \\
\hline 6 & PIKЗCA & c. $3073 \mathrm{~A}>\mathrm{G}$ & Tolerated & $\begin{array}{l}\text { Disease } \\
\text { causing }\end{array}$ & Deleterious & Deleterious & 23.2 & Likely pathogenic \\
\hline 7 & PIKЗCA & c. $2908 \mathrm{G}>\mathrm{A}$ & Tolerated & $\begin{array}{l}\text { Disease } \\
\text { causing }\end{array}$ & Neutral & Neutral & 22.8 & Likely pathogenic \\
\hline 8 & KRAS & c. $35 \mathrm{G}>\mathrm{A}$ & Deleterious & $\begin{array}{l}\text { Disease } \\
\text { causing }\end{array}$ & Deleterious & Deleterious & 25.3 & Pathogenic \\
\hline 9 & KRAS & c. $35 \mathrm{G}>\mathrm{A}$ & Deleterious & $\begin{array}{l}\text { Disease } \\
\text { causing }\end{array}$ & Deleterious & Deleterious & 25.3 & Pathogenic \\
\hline 10 & PTEN & c. $755 \mathrm{~A}>\mathrm{T}$ & Deleterious & $\begin{array}{l}\text { Disease } \\
\text { causing }\end{array}$ & Deleterious & Deleterious & 27.3 & Likely pathogenic \\
\hline 11 & MAP2K3 & c. $696+1 G>A$ & - & $\begin{array}{l}\text { Disease } \\
\text { causing }\end{array}$ & - & - & 26.8 & VUS \\
\hline 12 & $G N A Q$ & c. $548 \mathrm{G}>\mathrm{A}$ & Deleterious & $\begin{array}{l}\text { Disease } \\
\text { causing }\end{array}$ & Deleterious & Deleterious & 35 & Pathogenic \\
\hline 13 & TBC1D4 & c. $667 \mathrm{G}>\mathrm{A}$ & Deleterious & $\begin{array}{l}\text { Disease } \\
\text { causing }\end{array}$ & Deleterious & Deleterious & 34 & VUS \\
\hline 14 & TEK & c.3324_3334del & - & & - & - & - & Pathogenic \\
\hline
\end{tabular}

Among the 15 patients with lateralized overgrowth, the genetic diagnosis was PROS in 7 patients, RAS/MAPK-related OS in 3 patients, Proteus-like syndrome in 1 patient, and Sturge-Weber syndrome in 1 patient (Table 1). Further genetic evaluation of patient 15 was not available.

\section{Treatment outcomes}

Propranolol was administrated to 12 patients, except for three patients who did not want propranolol administration (Table 3). The total duration of treatment was $26 \pm 13.7$ months (range, $12-50$ months). The initial starting dose of propranolol was $0.76 \pm 0.29 \mathrm{mg} / \mathrm{kg} / \mathrm{day}$ (range, $0.4-1.3 \mathrm{mg} / \mathrm{kg} / \mathrm{day}$ ), and the escalated maximum dose, decided based on the patients' tolerance, was $3.2 \pm 1.1 \mathrm{mg} / \mathrm{kg} / \mathrm{day}$ (range, $0.5-4.0 \mathrm{mg} / \mathrm{kg} / \mathrm{day}$ ).

Seven patients experienced mild improvement of symptoms: relief of pain, extended range of motion, and a mild decrease in cutaneous swelling and capillary lesions (Table 4 and Fig. 1). The responses to the SF-36 version 2 of short-form health survey questionnaire were available in seven patients. The mean physical component score of SF-36 changed from $50.8 \pm 31.9$ to $65.1 \pm 23.3$ after propranolol treatment (Wilcoxon signed-rank test, $p=0.61$ ). The mental component score also changed from $58.4 \pm 25.1$ to $65.6 \pm 18.2$ (Wilcoxon signed-rank test, $p=0.86$ ). Three patients showed an improvement in SF-36 scores. However, there was no obvious improvement in the size of the lesions on regular follow-up of WB-MRI scans. Patients 5 and 11 showed aggravation of symptoms after discontinuing propranolol, but they regained the treatment effect again after re-introducing propranolol. Patient 5 showed improvement of cutaneous vascular symptoms with a 3-year administration of propranolol (Fig. 1). Three patients experienced transient side effects of dizziness or bradycardia, but they continued treatment at a lower dose. 
Table 4

Clinical profiles of patients receiving propranolol treatment.

\begin{tabular}{|c|c|c|c|c|c|c|c|c|c|c|}
\hline \multirow[t]{2}{*}{ Patient } & \multirow{2}{*}{$\begin{array}{l}\text { Maximum } \\
\text { dose } \\
(\mathrm{mg} / \mathrm{kg} / \text { day) }\end{array}$} & \multirow{2}{*}{$\begin{array}{l}\text { Duration } \\
\text { (month) }\end{array}$} & \multirow{2}{*}{$\begin{array}{l}\text { Adverse } \\
\text { event }\end{array}$} & \multirow{2}{*}{$\begin{array}{l}\text { Clinical } \\
\text { improvement }\end{array}$} & \multirow{2}{*}{$\begin{array}{l}\text { Composition } \\
\text { of the } \\
\text { improved } \\
\text { lesion }\end{array}$} & \multicolumn{2}{|c|}{ SF-36 physical score } & \multicolumn{2}{|c|}{ SF-36 mental score } & \multirow{2}{*}{$\begin{array}{l}\text { ESR }(\mathrm{mm} / \mathrm{hr}) \\
\text { Before } \\
\text { treatment }\end{array}$} \\
\hline & & & & & & $\begin{array}{l}\text { Before } \\
\text { treatment }\end{array}$ & $\begin{array}{l}\text { After } \\
\text { treatment }\end{array}$ & $\begin{array}{l}\text { Before } \\
\text { treatment }\end{array}$ & $\begin{array}{l}\text { After } \\
\text { treatment }\end{array}$ & \\
\hline 1 & 3 & 18 & Dizziness & None & - & - & - & - & - & 15 \\
\hline 2 & 1.8 & 12 & None & None & - & - & - & - & - & 2 \\
\hline 3 & 2.4 & 12 & $\begin{array}{l}\text { Bradycardia, } \\
\text { chest pain }\end{array}$ & $\begin{array}{l}\text { Relieved leg } \\
\text { pain }\end{array}$ & Vascular & 61.56 & 50.62 & 67.8 & 53.43 & 21 \\
\hline 5 & 3.3 & 44 & None & $\begin{array}{l}\text { Increased } \\
\text { shoulder } \\
\text { range of } \\
\text { motion, } \\
\text { improvement } \\
\text { in } \\
\text { ambulation, } \\
\text { decreased } \\
\text { varicosities }\end{array}$ & Vascular & 1.25 & 91.25 & 16.25 & 73.75 & 45 \\
\hline 6 & 4 & 21 & None & $\begin{array}{l}\text { Slight } \\
\text { improvement } \\
\text { of } \\
\text { hypertrophy }\end{array}$ & Vascular & - & - & - & - & 16 \\
\hline 7 & 4 & 41 & None & None & - & - & - & - & - & 2 \\
\hline 8 & 4 & 50 & None & None & - & 90 & 95 & 81.87 & 92.81 & 2 \\
\hline 10 & 3.6 & 21 & Dizziness & $\begin{array}{l}\text { Improved } \\
\text { skin } \\
\text { pigmentation }\end{array}$ & $\begin{array}{l}\text { Superficial } \\
\text { vein }\end{array}$ & 21.56 & 42.5 & 44.68 & 51.9 & 2 \\
\hline 11 & 4 & 39 & None & $\begin{array}{l}\text { Decreased } \\
\text { swelling of } \\
\text { leg }\end{array}$ & Venolymphatic & 72.5 & 63.43 & 87.81 & 72.18 & 10 \\
\hline 12 & 4 & 25 & None & $\begin{array}{l}\text { Decreased } \\
\text { skin } \\
\text { pigmentation }\end{array}$ & Venolymphatic & 72.18 & 73.75 & 67.29 & 65.93 & 34 \\
\hline 13 & 0.5 & 12 & None & $\begin{array}{l}\text { Decreased } \\
\text { swelling of } \\
\text { foot }\end{array}$ & Venolymphatic & - & - & - & - & 9 \\
\hline 15 & 4 & 17 & None & $\begin{array}{l}\text { Decreased } \\
\text { back pain, } \\
\text { increased } \\
\text { shoulder } \\
\text { range of } \\
\text { motion, } \\
\text { decreased } \\
\text { skin } \\
\text { pigmentation } \\
\text { of thigh }\end{array}$ & $\begin{array}{l}\text { Superficial } \\
\text { vein }\end{array}$ & 36.25 & 33.12 & 42.9 & 35 & 10 \\
\hline Average & $3.2 \pm 1.1$ & $\begin{array}{l}26 \pm \\
13.7\end{array}$ & & & - & $\begin{array}{l}50.8 \pm \\
31.9\end{array}$ & $\begin{array}{l}65.1 \pm \\
23.3\end{array}$ & $\begin{array}{l}58.4 \pm \\
25.1\end{array}$ & $\begin{array}{l}65.6 \pm \\
18.2\end{array}$ & $\begin{array}{l}15.1 \pm \\
13.8\end{array}$ \\
\hline$p$-value & & & & & - & 0.61 & & 0.86 & & 0.03 \\
\hline
\end{tabular}

SF-36, SF-36 version 2 of short-form health survey questionnaire; ESR, erythrocyte sedimentation rate

ESR was $15.1 \pm 13.8 \mathrm{~mm} / \mathrm{h}$ before treatment and decreased to $6.3 \pm 7.4 \mathrm{~mm} / \mathrm{h}$ at 12 months of treatment (Wilcoxon signed-rank test, $p=0.03$ ) (Table 4$)$. The cytokine levels were examined in nine patients, and the mean levels after treatment were compared with the initial levels. Although the changes in cytokines were not statistically significant, similar patterns of changes were observed in four patients (Additional File: Table S2 and Fig.S2). The levels of growth factors, such as epidermal growth factor, fibroblast growth factor 2, transforming growth factor alpha, and vascular endothelial growth factor, decreased. There were also changes in the factors related to the regulation of angiogenesis, such as decrease of fractalkine, soluble cluster of differentiation 40 ligand (sCD $40 \mathrm{~L}$ ), and increase of interferon gamma induced protein 10 (IP-10).

Alpelisib was administrated for 18 months in patients 2 and 3 , who had a somatic PIK3CA mutation and hypertrophy of the extremities. There were no specific adverse events during the study period, and drug administration was continued. Patient 2 had a lateralized overgrowth of the left leg and was 10 years old at the start of the clinical trial (50 mg qd). In patient 2 who was a growing child, the volumes of the left and right leg before treatment were $8351.6 \mathrm{~cm}^{3}$ and $7758.6 \mathrm{~cm}^{3}$, respectively. After 1 year of treatment with alpelisib, the volumes of the left and right leg increased to $9013.2 \mathrm{~cm}^{3}$ and $8542.2 \mathrm{~cm}^{3}$, respectively. The volume increase rate of the left and right leg were $7.9 \%$ and $10.1 \%$, respectively. There was a $7.6 \%$ difference between the volumes of both legs before treatment, but this difference slightly decreased to $5.5 \%$ after 1 year of treatment. Patient 3 had hypertrophy of both lower legs and was 42 years old at the start of the clinical trial (250 mg qd). In patient 3, the volumes of the left and right leg before treatment were $19867.3 \mathrm{~cm}^{3}$ and $18239.1 \mathrm{~cm}^{3}$, respectively. After 
1 year of treatment with alpelisib the volumes of the left and right leg decreased to $18000.9 \mathrm{~cm}^{3}$ and $16570.3 \mathrm{~cm}^{3}$, respectively. The volume decrease rates of the left and right leg were $9.4 \%$ and $9.1 \%$, respectively (Fig. 2).

\section{Discussion}

The current study described the molecular genetic analysis of patients with lateralized overgrowth. By utilizing deep sequencing of the genes related to the PIK3CA/AKT/mTOR and RAS/MAPK pathways, we could expand the known genetic variants of this condition. Moreover, by comparing the VAF in the affected tissues to that in the normal tissues, we could detect mutations with low levels of mosaicism.

Most of our patients were identified as having PROS, but KRAS, PTEN, MAP2K3, GNAQ, TBC1D4, and TEK mutations were also identified. Careful physical examination of dysmorphic features can help to identify a recognizable pattern in some cases, but differential diagnosis is challenging in other cases because of the variety of overlapping phenotypes between the disorders with lateralized overgrowth. The degree of mosaicism varies widely from individual to individual, and the diverse phenotypes also makes it difficult to diagnose. In these cases, genome testing and methylation studies can enable differential diagnosis. To improve the genetic detection rate, the affected tissue, such as vascular malformation tissue, should be obtained. In addition, as the mutation exists in a mosaic pattern, deep sequencing using massively parallel sequencing techniques needs to be applied. Therefore, targeted gene panel testing with deep sequencing is preferential to whole exome sequencing for the genetic diagnosis of lateralized overgrowth. The overall molecular diagnostic yield of OS has been reported as up to $45 \%$ in the affected tissues ${ }^{20}$. In the present study, a customized panel was used to sequence as many genes as possible that are related to the PIK3CA/AKT/mTOR and RAS/MAPK pathways (the mean depth of coverage was 878 reads per base) and thereby enhance the overall genetic detection rate. Consequently, we were able to identify genetic defects in most of our patients. Methylation defects may be the cause in some patients, so methylation studies should be considered if the causative gene is not identified by exome sequencing. Unfortunately, no additional methylation test was performed on patient 15 .

The levels of mosaicism can be as low as $<5 \%$ in the affected tissues of patients with PROS ${ }^{21}$. In the present study, additional deep-sequencing tests with blood samples were helpful in diagnosing seven patients with low levels of mosaicism. Germline filtering also help to identify germline mutations, as in patient 10 of our study 22 .

The association between the genetic variants and overgrowth in the patients in the present study is supported by multiple observations. All the variants found in the present study have not been reported in the normal population but, importantly, have been identified in the affected tissues of the enrolled patients. Furthermore, using multiple in silico prediction tools and per the ACMG guidelines, these variants are predicted to alter the protein function ${ }^{14}$. Besides PIK3CA, variants related to the RAS/MAPK pathway were identified in KRAS and MAP2K3 mutations in three patients. Mosaic Ras/MAPK variants are related to vascular malformation ${ }^{18}$. The MAP2K3 variant found in our study has not been reported, but considering the cell proliferation function and correlation with tumorigenesis of MAP2K3 ${ }^{23}$, it could have a relation with overgrowth. The germline PTEN mutation (in patient 10) causes epidermal nevus and mild vascular malformation of the buttock and thigh that is associated with PTEN related Proteus syndrome. The high VAF of 0.7 from the blood sample in this patient might have resulted from partial deletion or second hit of the wild-type PTEN allele ${ }^{24}$. The GNAQ mutation in patient 12 explains the capillary malformation involving OS observed in Sturge-Weber syndrome ${ }^{25-27}$. The TEK mutation in patient 13 can cause multiple sporadic venous malformations ${ }^{19,28,29}$. Although the association between the TBC1D4 mutation and lateralized overgrowth in patient 14 is not clear, the same somatic mutation has been reported in large intestinal adenocarcinoma tissue ${ }^{30}$. TBC1D4 is a GTPase-activating protein that functions downstream of AKT and seems to regulate the proliferation of multiple cell types ${ }^{31-33}$

The present study is the first to evaluate the efficacy of propranolol in patients with lateralized overgrowth. Although no significant improvement was observed in the affected areas following propranolol treatment, some patients experienced improvement of pain, range of motion, cutaneous symptoms, inflammation (ESR), and quality of life. Notably, rapid worsening of symptoms was observed in some patients after discontinuation of propranolol. Importantly, key cytokine levels tended to change in a similar pattern in four patients after propranolol administration. The levels of growth factors and SCD40L, which is known to produce angiogenesis-associated factors ${ }^{34-36}$, decreased. The cytokine IP-10, which blocks vascular endothelial growth factor-induced endothelial motility and angiogenesis ${ }^{37,38}$, tended to increase with propranolol. IP-10 can also enhance the anticancer activity of agents targeting tumor vasculature in soft tissue sarcomas ${ }^{39}$. Recent research suggests that propranolol can inhibit activity of the PI3K and AKT pathways ${ }^{9,10}$. Further research involving larger participants is needed to identify the mechanism of cytokine changes. Taken together, propranolol may regulate the cytokines related to angiogenesis and subtly reduce the burdens caused by vascular malformations. Propranolol is a drug with uncommon side effects; therefore, it could be used as an adjunct to relieve vascular symptoms in patients with lateralized overgrowth.

The mTOR inhibitor sirolimus has been clinically administered at low doses and showed a modest reduction in OS symptoms. However, $72 \%$ of participants had at least one adverse event; therefore, risk-benefit evaluations must be carefully considered ${ }^{40}$. The PIK3CA inhibitor alpelisib has been undergoing clinical trials for several PIK3CA-dependent tumors and PROS ${ }^{4,5,41}$. The use of alpelisib has been approved for certain advanced or metastatic breast cancer ${ }^{42}$, but only a few reports exist regarding its application in patients with PROS. The first evidence for the use of alpelisib in patients with PROS showed promising efficacy and no substantial side effects ${ }^{4}$. There was an improvement in vascular tumor size, congestive heart failure, lateralized overgrowth and scoliosis ${ }^{4}$. The two patients with PROS in the present study participating in the alpelisib MAP ${ }^{43}$ experienced a reduction in the degree of hypertrophy after administration for 1 year. There were no side effects in these patients following an 18-months trial of alpelisib. Nonetheless, some common side effects of alpelisib include hyperglycemia, diarrhea, nausea, fatigue, stomatitis, and pneumonitis, and patients should therefore be carefully monitored ${ }^{42}$. PI3K/AKT/mTOR inhibitors would also affect the metabolism of healthy cells ${ }^{3}$, and the need for life-long therapy with these inhibitors raises concerns of unknown side effects. Further research on the treatment of patients with PROS with alpelisib is required to dispel these concerns.

Page $8 / 11$ 
Several limitations should be addressed in the present study. Although most of the identified mutations have also been found in vascular malformation tissues of other literatures, more evidence is needed to prove their association with overgrowth. The low levels of mosaicism in some patients means that the causality of the mutation remains elusive. The alleles with mosaic mutations could be present in only a subset of cells, and the causative variant can easily be missed without a precise technical procedure. The depth of sequencing was relatively low to detect all the potential mosaic variants in this study. Achieving a much higher reading depth is needed to increase the low frequency fraction variant detection sensitivity of mosaicism and avoid misinterpretation ${ }^{44,45}$. As an open-label, non-randomized, observational study, the objective evaluation of the efficacy of propranolol was impossible. Although alpelisib showed promising efficacy, compared to a fixed dose of $250 \mathrm{mg}$ in an adult patient, its pediatric dosage has not been established. To prove the efficacy of alpelisib in children, an appropriate dosage should be determined and administrated according to body weight.

In conclusion, customized panel-gene deep-sequencing enhanced the genetic diagnosis in patients with lateralized overgrowth syndrome, which furthermore identified the novel genetic cause, MAP2K3 and TBC1D4 mutations in this condition. Propranolol could be used as an adjuvant therapy for decreasing vascular symptoms in lateralized overgrowth patients. Targeted therapy considering genetic causes would be the leading therapeutic strategy of overgrowth syndrome in the future.

\section{Declarations}

\section{Ethics approval and consent to participate}

The study was approved by the Institutional Review Board of Asan Medical Center (no. 2020-1628). Written informed consent was obtained from all participants and all methods were performed in accordance with the relevant guidelines and regulations.

\section{Consent for publication}

No personally identifiable data is contained in this article.

\section{Availability of data and materials}

All data supporting the presented results are included in this published article. The raw data of whole-exome sequencing of the patient in this study are not publicly available to protect participant confidentiality, but they are available from the corresponding author on reasonable request. Please contact Professor $\mathrm{BH}$ Lee at the Department of Medical Genetics in the Asan Medical Center Children's hospital for any requests to access the data. Reference sequences for PIK3CA (NC_000003.12), KRAS(NC_000012.12), PTEN(NC_000010.11), MAP2K3 (NC_000017.11), GNAQ (NC_000009.12), TBC1D4 (NC_000013.11) and TEK (NC_000009.12) are available in the GenBank repository. The links to the GenBank repositories are as follows;

PIK3CA(https://www.ncbi.nlm.nih.gov/nuccore/NC_000003.12?from=179148126\&to=179240093\&report=genbank),

KRAS(https://www.ncbi.nlm.nih.gov/nuccore/NC_000012.12?from=25205246\&to=25250929\&report=genbank\&strand=true),

PTEN(https://www.ncbi.nlm.nih.gov/nuccore/NC_000010.11?from=87863625\&to=87971930\&report=genbank),

MAP2K3(https://www.ncbi.nlm.nih.gov/nuccore/NC_000017.11?from=21284711\&to=21315240\&report=genbank),

GNAQ(https://www.ncbi.nlm.nih.gov/nuccore/NC_000009.12?from=77716097\&to=78031811\&report=genbank\&strand=true),

TBC1D4(https://www.ncbi.nlm.nih.gov/nuccore/NC_000013.11?from=75283503\&to=75482169\&report=genbank\&strand=true), and

TEK(https://www.ncbi.nlm.nih.gov/nuccore/NC_000009.12?from=27109141\&to=27230178\&report=genbank).

\section{Competing interests}

The authors report no disclosures relevant to the manuscript.

\section{Funding}

This research was supported in part by the Bio \& Medical Technology Development Programme of the national research Foundation (NRF) funded by the Korean government (NRF-2018M3A9H1078335).

\section{Authors' contributions}

YK, MY, HY and BL contributed to designing the study. YK, YL, YC and BL were the clinicians who conducted all clinical and radiological examinations. SH, JC and $\mathrm{HD}$ did the laboratory experiments. BL, YK, YL, YC, JJ, and MY analyzed the data. YK, JJ, MY and BL drafted the manuscript and HY, BL revised the manuscript. All authors were involved in analyzing and interpreting the data. All authors read and approved the final manuscript.

Acknowledgments: We deeply appreciate the patients and their families for participating in this study and the Novartis Pharmaceutical Corporation for the managed access program.

\section{References}

1. Brioude, F. et al. Overgrowth syndromes - clinical and molecular aspects and tumour risk. Nat. Rev. Endocrinol. 15, 299-311, doi:10.1038/s41574-0190180-z (2019).

2. Burkardt, D. D., Tatton-Brown, K., Dobyns, W. \& Graham, J. M., Jr. Approach to overgrowth syndromes in the genome era. Am. J. Med. Genet. C Semin. Med. Genet. 181, 483-490, doi:10.1002/ajmg.c.31757 (2019). 
3. Keppler-Noreuil, K. M., Parker, V. E., Darling, T. N. \& Martinez-Agosto, J. A. Somatic overgrowth disorders of the PI3K/AKT/mTOR pathway \& therapeutic strategies. Am. J. Med. Genet. C Semin. Med. Genet. 172, 402-421, doi:10.1002/ajmg.c.31531 (2016).

4. Venot, Q. et al. Targeted therapy in patients with PIK3CA-related overgrowth syndrome. Nature 558, 540-546, doi:10.1038/s41586-018-0217-9 (2018).

5. López Gutiérrez, J. C. et al. Alpelisib Treatment for Genital Vascular Malformation in a Patient with Congenital Lipomatous Overgrowth, Vascular Malformations, Epidermal Nevi, and Spinal/Skeletal Anomalies and/or Scoliosis (CLOVES) Syndrome. J. Pediatr. Adolesc. Gynecol. 32, 648-650, doi:10.1016/j.jpag.2019.07.003 (2019).

6. Lin, Z., Wang, L., Huang, G., Wang, W. \& Lin, H. Propranolol inhibits the activity of PI3K, AKT, and HIF-1alpha in infantile hemangiomas. Pediatr. Surg. Int. 34, 1233-1238, doi:10.1007/s00383-018-4347-9 (2018).

7. Li, D., Li, P., Guo, Z., Wang, H. \& Pan, W. Downregulation of miR-382 by propranolol inhibits the progression of infantile hemangioma via the PTENmediated AKT/mTOR pathway. Int. J. Mol. Med. 39, 757-763, doi:10.3892/ijmm.2017.2863 (2017).

8. Tan, S. T. et al. Treatment of infantile haemangioma with captopril. Br. J. Dermatol. 167, 619-624, doi:10.1111/j.1365-2133.2012.11016.x (2012).

9. Pföhler, C., Janssen, E., Buecker, A., Vogt, T. \& Müller, C. S. Successful treatment of a congenital extra-truncal vascular malformation by orally administered propranolol. J. Dermatolog. Treat. 26, 59-62, doi:10.3109/09546634.2013.869301 (2015).

10. Wu, J. K. et al. Initial Experience With Propranolol Treatment of Lymphatic Anomalies: A Case Series. Pediatrics 138, doi:10.1542/peds.2015-4545 (2016).

11. Li H. Aligning sequence reads, clone sequences and assembly contigs with BWA-MEM. https://doi.org/10.48550/arXiv.1303.3997 (2013).

12. McKenna, A. et al. The Genome Analysis Toolkit: a MapReduce framework for analyzing next-generation DNA sequencing data. Genome Res. 20, 12971303, doi:10.1101/gr.107524.110 (2010).

13. Ware JE. et al. User's Manual For The SF36v2 Health Survey (2nd ed.). (Lincoln, RI. Quality Metric Incorporated, 2007).

14. Richards, S. et al. Standards and guidelines for the interpretation of sequence variants: a joint consensus recommendation of the American College of Medical Genetics and Genomics and the Association for Molecular Pathology. Genet. Med. 17, 405-424, doi:10.1038/gim.2015.30 (2015).

15. Tate, J. G. et al. COSMIC: the Catalogue Of Somatic Mutations In Cancer. Nucleic Acids Res. 47, D941-d947, doi:10.1093/nar/gky1015 (2019).

16. Kuentz, P. et al. Molecular diagnosis of PIK3CA-related overgrowth spectrum (PROS) in 162 patients and recommendations for genetic testing. Genet. Med. 19, 989-997, doi:10.1038/gim.2016.220 (2017).

17. Mirzaa, G. et al. PIK3CA-associated developmental disorders exhibit distinct classes of mutations with variable expression and tissue distribution. JCl Insight 1, doi:10.1172/jci.insight.87623 (2016).

18. Al-Olabi, L. et al. Mosaic RAS/MAPK variants cause sporadic vascular malformations which respond to targeted therapy. J. Clin. Invest. 128, 1496-1508, doi:10.1172/jci98589 (2018).

19. Soblet, J., Limaye, N., Uebelhoer, M., Boon, L. M. \& Vikkula, M. Variable Somatic TIE2 Mutations in Half of Sporadic Venous Malformations. Mol. Syndromol. 4, 179-183, doi:10.1159/000348327 (2013).

20. Lalonde, E. et al. Molecular diagnosis of somatic overgrowth conditions: A single-center experience. Mol. Genet. Genomic Med. 7, e536, doi:10.1002/mgg3.536 (2019).

21. Keppler-Noreuil, K. M. et al. PIK3CA-related overgrowth spectrum (PROS): diagnostic and testing eligibility criteria, differential diagnosis, and evaluation. Am. J. Med. Genet. A 167a, 287-295, doi:10.1002/ajmg.a.36836 (2015).

22. Zollino, M. et al. Germline pathogenic variant in PIK3CA leading to symmetrical overgrowth with marked macrocephaly and mild global developmental delay. Mol. Genet. Genomic Med. 7, e845, doi:10.1002/mgg3.845 (2019).

23. Baldari, S., Ubertini, V., Garufi, A., D'Orazi, G. \& Bossi, G. Targeting MKK3 as a novel anticancer strategy: molecular mechanisms and therapeutical implications. Cell Death Dis. 6, e1621, doi:10.1038/cddis.2014.591 (2015).

24. Loffeld, A. et al. Epidermal naevus in Proteus syndrome showing loss of heterozygosity for an inherited PTEN mutation. Br. J. Dermatol. 154, 1194-1198, doi:10.1111/j.1365-2133.2006.07196.x (2006).

25. Shirley, M. D. et al. Sturge-Weber syndrome and port-wine stains caused by somatic mutation in GNAQ. N. Engl. J. Med. 368, 1971-1979, doi:10.1056/NEJMoa1213507 (2013).

26. Nakashima, M. et al. The somatic GNAQ mutation c.548G > A (p.R183Q) is consistently found in Sturge-Weber syndrome. J. Hum. Genet. 59, 691-693, doi:10.1038/jhg.2014.95 (2014).

27. Couto, J. A. et al. Endothelial Cells from Capillary Malformations Are Enriched for Somatic GNAQ Mutations. Plast Reconstr. Surg. 137, 77e-82e, doi:10.1097/prs.0000000000001868 (2016).

28. Limaye, N. et al. Somatic mutations in angiopoietin receptor gene TEK cause solitary and multiple sporadic venous malformations. Nat. Genet. 41, 118124, doi:10.1038/ng.272 (2009).

29. Soblet, J. et al. Blue Rubber Bleb Nevus (BRBN) Syndrome Is Caused by Somatic TEK (TIE2) Mutations. J. Invest. Dermatol. 137, 207-216, doi:10.1016/j.jid.2016.07.034 (2017).

30. Giannakis, M. et al. Genomic Correlates of Immune-Cell Infiltrates in Colorectal Carcinoma. Cell Rep. 15, 857-865, doi:10.1016/j.celrep.2016.03.075 (2016).

31. Gongpan, P., Lu, Y., Wang, F., Xu, Y. \& Xiong, W. AS160 controls eukaryotic cell cycle and proliferation by regulating the CDK inhibitor p21. Cell Cycle 15, 1733-1741, doi:10.1080/15384101.2016.1183853 (2016).

32. Bouzakri, K. et al. Rab GTPase-activating protein AS160 is a major downstream effector of protein kinase B/Akt signaling in pancreatic beta-cells. Diabetes 57, 1195-1204, doi:10.2337/db07-1469 (2008). 
33. Jiang, X. H. et al. Frequent hyperphosphorylation of AS160 in breast cancer. Cancer Biol. Ther. 10, 362-367, doi:10.4161/cbt.10.4.12426 (2010).

34. Dormond, O. et al. CD40-induced signaling in human endothelial cells results in mTORC2- and Akt-dependent expression of vascular endothelial growth factor in vitro and in vivo. J. Immunol. 181, 8088-8095, doi:10.4049/jimmunol.181.11.8088 (2008).

35. Melter, M. et al. Ligation of CD40 induces the expression of vascular endothelial growth factor by endothelial cells and monocytes and promotes angiogenesis in vivo. Blood 96, 3801-3808 (2000).

36. Danese, S. et al. Critical role of the CD40 CD40-ligand pathway in regulating mucosal inflammation-driven angiogenesis in inflammatory bowel disease. Gut 56, 1248-1256, doi:10.1136/gut.2006.111989 (2007).

37. Bodnar, R. J., Yates, C. C. \& Wells, A. IP-10 blocks vascular endothelial growth factor-induced endothelial cell motility and tube formation via inhibition of calpain. Circ. Res. 98, 617-625, doi:10.1161/01.Res.0000209968.66606.10 (2006).

38. Yates-Binder, C. C. et al. An IP-10 (CXCL10)-derived peptide inhibits angiogenesis. PLoS One 7, e40812, doi:10.1371/journal.pone.0040812 (2012).

39. Carew, J. S. et al. Oncolytic reovirus inhibits angiogenesis through induction of CXCL10/IP-10 and abrogation of HIF activity in soft tissue sarcomas. Oncotarget 8, 86769-86783, doi:10.18632/oncotarget.21423 (2017).

40. Parker, V. E. R. et al. Safety and efficacy of low-dose sirolimus in the PIK3CA-related overgrowth spectrum. Genet. Med. 21, 1189-1198, doi:10.1038/s41436-018-0297-9 (2019).

41. André, F. et al. Alpelisib for PIK3CA-Mutated, Hormone Receptor-Positive Advanced Breast Cancer. N. Engl. J. Med. 380, 1929-1940, doi:10.1056/NEJMoa1813904 (2019).

42. Markham, A. Alpelisib: First Global Approval. Drugs 79, 1249-1253, doi:10.1007/s40265-019-01161-6 (2019).

43. Managed Access Program (MAP) to Provide Alpelisib (BYL719) for Patients With PIK3CA-Related Overgrowth Spectrum (PROS). Identifier NCT04085653. http://clinicaltrials.gov/ct2/show/NCT04085653 (2019).

44. Contini, E. et al. A Systematic Assessment of Accuracy in Detecting Somatic Mosaic Variants by Deep Amplicon Sequencing: Application to NF2 Gene. PLoS One 10, e0129099, doi:10.1371/journal.pone.0129099 (2015).

45. Qin, L. et al. Detection and Quantification of Mosaic Mutations in Disease Genes by Next-Generation Sequencing. J. Mol. Diagn. 18, 446-453, doi:10.1016/j.jmoldx.2016.01.002 (2016).

\section{Figures}

\section{Figure 1}

Clinical manifestations of patients.

(A) Patient 5 with a PIK3CA mutation with prominent superficial venous engorgement. The superficial venous engorgement showed improvement after 3 years of propranolol administration. (B) Patient 1 with a PIK3CA mutation showing port-wine stain of the skin and hypertrophy of the right leg. (C) Patient 10 with a PTEN mutation presented with epidermal nevus. The color of the epidermal nevus faded after 6 months of propranolol administration. (D) Patient 9 with a KRAS mutation showing hypertrophy of the right leg.

\section{Figure 2}

Change in the MRI findings of patient 3 after the administration of alpelisib. (A) The MRI image of both lower legs before treatment (B) The MRI image of both legs after treatment. The extent of fine stranding of the subcutaneous layer of the bilateral distal lower legs decreased. Minimal improvement of the tortuous and dilated deep and superficial venous structure in the lower extremities was observed.

\section{Supplementary Files}

This is a list of supplementary files associated with this preprint. Click to download.

- SupplementarymaterialLOS.docx 